\title{
Índice de Funcionalidade Brasileiro: percepções de profissionais e pessoas com deficiência no contexto da LC 142/2013
}

\author{
The Brazilian Functionality Index: \\ perceptions of professionals and persons with disabilities \\ in the context of Complementary Law 142/2013
}

Éverton Luís Pereira ${ }^{1}$ Livia Barbosa ${ }^{1}$
${ }^{1}$ Departamento de Saúde Coletiva, Universidade de Brasília. Campus Universitário Darcy Ribeiro s/n, Asa Norte. 70910-900 Brasília DF Brasil. everton.epereira@gmail.com

\begin{abstract}
This article derives from a study conducted on the validation of the Brazilian Functionality Index (IF-BrA) applied to the granting of retirement benefits to disabled persons. The retirement of persons with disabilities is regulated by Complementary Law 142 of May 8, 2013. The aim is to discuss how the individuals involved in application of the instrument perceive the concept of disability and the possible implications for ensuring the right to retirement. Eleven agencies of the National Social Security Institute (INSS) were visited and 16 physicians, 16 social workers and 40 persons with disabilities were interviewed. The evaluation and assessment process was also observed. The results indicate that there are conceptual tensions between the perspective on disability of the professionals and the IF-BrA concepts. Social workers and physicians are challenged in their technical specialties in the application of the instrument. Persons with disabilities do not always consider themselves to be disabled in their daily lives. Disability is either presented as a political description of the body in accordance with the social model of disability, or it is described as a specific difficulty justifying the right to seek retirement.
\end{abstract}

Key words Brazilian Functionality Index, Complementary Law 142/2013, Retirement, Persons with disabilities, Disability studies
Resumo O artigo resulta de estudo realizado na validação do Índice de Funcionalidade Brasileiro, aplicado para fins de concessão da aposentadoria da pessoa com deficiência (IFBrA). A aposentadoria é regulamentada pela Lei Complementar 142/2013. O objetivo é discutir como os sujeitos envolvidos na aplicação do instrumento fazem uso do conceito de deficiência e as possíveis implicações para a garantia do direito à aposentadoria. Foram visitadas 11 agências do Instituto Nacional do Seguro Social (INSS), onde foram entrevistados 16 peritos médicos, 16 assistentes sociais e 40 pessoas com deficiência, além de observadas a avaliação e a perícia. Os resultados indicam tensões conceituais entre a perspectiva sobre deficiência dos profissionais e os conceitos do IFBrA. Assistentes sociais e médicos são desafiados em suas especialidades técnicas na aplicação do instrumento. As pessoas com deficiência nem sempre se identificam assim em suas vidas diárias. A deficiência ora écolocada como uma descrição politica dos corpos em consonância com o modelo social da deficiência, ora é descrita como uma dificuldade pontual que justifica a busca pela aposentadoria.

Palavras-chave Índice de Funcionalidade Brasileiro, Lei Complementar 142/2013, Aposentadoria, Pessoas com deficiência, Estudos sobre deficiência 


\section{Introdução}

O artigo é resultado de pesquisa realizada no Instituto Nacional do Seguro Social (INSS) durante a implementação da Lei Complementar 142 de 2013, que institui a aposentadoria de pessoas com deficiência pelo Regime Geral da Previdência. A pesquisa trata da validação do Índice de Funcionalidade Brasileiro aplicado para fins de aposentadoria da pessoa com deficiência (IFBrA), instrumento destinado a identificar os sujeitos elegíveis a aposentadoria. O objetivo do artigo é discutir as formas como os sujeitos envolvidos na aplicação do Índice (assistentes sociais, peritos médicos e segurados) fazem uso do conceito de deficiência e quais são as possíveis implicações para a garantia do direito à aposentadoria da pessoa com deficiência para aqueles que a procuram. No Brasil, desde 2013, as pessoas com deficiência podem se aposentar dois, seis ou dez anos mais cedo do que as demais a depender do grau de deficiência (leve, moderada ou grave), este atribuído em conjunto com médicos e assistentes sociais do INSS por meio do uso do IFBrA $^{1}$. Esse direito está previsto no $₫ 1^{\circ}$ do art. 201 da Constituição Federal e foi regulamentado por meio da LC 142/2013.

Fazemos uso das teorias oriundas dos estudos da deficiência. Neste campo, a deficiência é definida como uma forma de opressão. Podemos dizer que ela sempre esteve presente nas agendas das políticas públicas das sociedades contemporâneas. As pessoas com deficiência foram historicamente excluídas de várias esferas da vida social, exigindo formas distintas de atenção coletiva. A partir de meados do século XX, ganham força as demandas deste segmento, especialmente pela sistematização e formalização de suas pautas políticas. O debate sobre a deficiência emerge em resposta às dificuldades das ações disponíveis em enfrentar desigualdades sofridas por este grupo populacional. O desafio da intervenção pública em matéria de deficiência passa a ser pauta compartilhada entre militância política, investigação acadêmica e gestão social.

A Convenção sobre os Direitos das Pessoas com Deficiência é considerada um marco político e jurídico importante no que diz respeito aos direitos das pessoas com deficiência ${ }^{2}$. Adotada pelas Nações Unidas em 2006, passa a ser um documento estruturante e referência para os países signatários. O Brasil ratificou a Convenção em 2007 e conferiu status constitucional ao seu texto em 2008. Com a entrada da Convenção no ordenamento jurídico brasileiro, as políticas so- ciais foram desafiadas a se adequar ao texto então constitucional por meio da revisão progressiva dos seus marcos normativos.

Dentre os desafios colocados na Convenção, ganha notoriedade o debate sobre a definição de deficiência. Pauta controversa dos chamados estudos sobre deficiência (disability studies), a definição transita entre, pelo menos, dois modelos - um biomédico e um social - que apresentam explicações e soluções distintas para a desigualdade entre pessoas com e sem deficiência.

No modelo médico é o corpo individual que deve ser cuidado e tratado por meio de técnicas de reabilitação. Nesse modelo, a deficiência é uma tragédia pessoal. Estatísticas são utilizadas para demonstrar o quão distante da curva de normalidade essas pessoas se encontram e a doença é a maneira de explicar a deficiência ${ }^{3}$.

O modelo social coloca em xeque o predomínio biomédico na explicação da deficiência ${ }^{4}$. Para os autores que se dedicam a esse marco conceitual, a deficiência não é uma questão meramente biomédica, mas social ${ }^{3-7}$. O argumento é de que a deficiência não é apenas corporal, mas resultado da interação entre o corpo com impedimentos e a sociedade que o desconsidera para a construção das dimensões da vida social ${ }^{8}$. Assim, a deficiência é um produto sócio-histórico da interação entre um corpo diverso e uma sociedade pouco aberta e pouco preparada para a diversidade.

Para a Convenção, deficiência é um conceito dinâmico e permeável pelas determinações sociais e diz respeito às restrições de participação sofridas por pessoas com impedimentos corporais em ambientes com barreiras. Assim, deficiência é assumida como um desafio de justiça como paridade participativa, e as barreiras foram identificadas como a principal causa das desigualdades sofridas. A Convenção descreve a discriminação por motivo de deficiência como qualquer diferenciação que prejudique o reconhecimento, o desfrute ou o exercício da igualdade de oportunidades ou de direitos das pessoas com deficiência em qualquer âmbito da vida so$\mathrm{cial}^{2}$.

Para fazer frente às demandas colocadas pela Convenção, a Secretaria de Direitos Humanos da Presidência da República providenciou a construção de um instrumento para a identificação das pessoas com deficiência para os fins da proteção social no país. O Instituto de Estudos do Trabalho e Sociedade, da UFRJ, elaborou o referido instrumento, que passou a ser conhecido pelo nome de Índice de Funcionalidade Brasileiro ou IFBr' . 


\section{Índice de Funcionalidade Brasileiro (IFBr)}

É um instrumento que lista 41 atividades distribuídas entre sete domínios. Cada atividade do instrumento é avaliada por pontuações que consideram a dependência dos sujeitos avaliados em relação a outras pessoas ou a produtos e tecnologias no seu desempenho. As atividades são baseadas na Classificação Internacional de Funcionalidade, Incapacidade e Saúde (CIF), e a pontuação é uma adaptação da Medida de Independência Funcional (MIF), documentos reconhecidos internacionalmente para a discussão sobre deficiência e saúde coletiva.

A avaliação de cada atividade é realizada por meio de quatro pontuações (100, 75, 50 e 25) em que 100 representa a completa independência funcional e 25 a não execução da atividade ou a completa dependência de terceiros. As pontuações intermediárias são 75, atribuída aos sujeitos que executam as atividades com o auxílio de tecnologias assistivas ou de forma diferente da considerada usual; e 50, conferida quando é necessário o auxílio, a supervisão ou a preparação de alguma etapa da atividade por terceiros.

A Lei 13.146, de 6 de julho de 2015 (Lei Brasileira de Inclusão), exige que o executivo promulgue instrumento específico para identificação dos sujeitos com deficiência para todas as políticas sociais no Brasil. O IFBr tem o potencial de ser o instrumento base para a construção do modelo unificado, de forma que deverá ser apropriado e adequado a cada política social até janeiro de $2018^{10}$. Os dados deste artigo se referem ao primeiro processo de validação do IFBr, que foi adequado à política de previdência e ao seu público-alvo cuja versão adaptada chama-se $\mathrm{IFBrA}^{11}$. O instrumento original, no entanto, deverá passar por validações internas a cada política pública.

\section{Métodos}

Os resultados apresentados são parte da pesquisa de Validação do IFBrA. A validação do instrumento ocorreu em três fases (conteúdo, face e acurácia) e os dados apresentados dizem respeito à segunda fase, correspondente à validação de face do instrumento. O objetivo da pesquisa foi analisar os cenários da perícia médica e da avaliação social que identificam o sujeito com deficiência para fins de elegibilidade para a LC 142/2013. Para tanto, foi utilizada a combinação de duas técnicas de pesquisa: a observação das cenas da perícia médica e da avaliação social e entrevistas individuais com os sujeitos participantes dessas cenas, configurando assim a triangulação metodológica $^{12-14}$.

A coleta dos dados foi realizada em, pelo menos, duas agências do INSS de cada uma das regiões brasileiras, sendo uma na capital e outra no interior, uma de grande porte e outra de pequeno ou médio porte, de acordo com as definições e configurações próprias da instituição. $\mathrm{O}$ critério de seleção foi a concentração dos agendamentos para atendimento das pessoas com deficiência.

O projeto foi aprovado pelo CEP da Faculdade de Ciências da Saúde da UnB. Foi preservado o anonimato de todos os participantes e garantido a cada um o direito de não participação ou desistência em qualquer etapa da pesquisa. Foi aplicado o Termo de Consentimento Livre e Esclarecido para todos, conforme previsto na Resolução CNS 466/12.

Foram entrevistados 16 peritos médicos, 16 assistentes sociais e 40 pessoas com deficiência que pleiteavam a aposentadoria em todas as regiões do Brasil. Foram utilizados roteiros semiestruturados específicos para cada tipo social, divididos em blocos que buscaram compreender as trajetórias individuais, as concepções sobre deficiência e a LC 142/2013 e as percepções sobre o IFBrA e sua aplicação.

As entrevistas foram analisadas de forma a contemplar as categorias emergentes nos discursos dos sujeitos da pesquisa, utilizando a teoria fundamentada nos dados ${ }^{15}$. Essa proposta de análise se produz pela revisão do material coletado em campo e na identificação de elementos importantes para os participantes, possibilitando a construção de teorias por meio dos dados.

\section{Resultados e discussão}

A proposta é apresentar as considerações iniciais obtidas nas entrevistas com os sujeitos envolvidos na LC 142/2013, especialmente sobre as concepções de deficiência e os seus impactos na aplicação e compreensão do IFBrA. Serão realizadas discussões sobre cada um dos tipos sociais entrevistados de forma particular, peritos médicos, assistentes sociais e pessoas com deficiência.

Cada uma das categorias profissionais apresentou particularidades nas concepções de deficiência. Visto que o propósito deste artigo é de reconhecer como os conceitos são instrumentalizados na aplicação do IFBrA, as entrevistas serviram como elementos para o reconhecimento das 
formas como cada categoria utiliza essas questões em seus cotidianos.

Os três tipos sociais que serão detalhados a seguir foram igualmente importantes para o argumento do artigo, justamente por serem atores chave no uso do instrumento. Os dois primeiros, assistentes sociais e peritos médicos, são responsáveis pela tarefa da realização da avaliação do segurado. São eles que utilizam o IFBrA. As pessoas com deficiência, por outro lado, são submetidas às avaliações e realizam reflexões sobre o momento pericial e sobre a importância do instrumento na definição de deficiência.

Os resultados indicam que há tensão entre os conceitos sociais e biomédicos sobre a deficiência entre os profissionais entre si e com os conceitos presentes no instrumento. As pessoas com deficiência, por sua vez, muitas vezes não se identificam como "pessoas com deficiência" em suas vidas diárias. As análises aqui realizadas evidenciam essas tensões e apontam desafios para a avaliação da deficiência para a aposentadoria no Brasil.

\section{Assistentes sociais}

A experiência do Serviço Social do INSS com o debate da deficiência ganha força com a publicação do Decreto 6214/2007, que regulamenta o Benefício de Prestação Continuada da Assistência Social $(\mathrm{BPC})^{16,17}$. A demanda normativa da avaliação social desafiou o Serviço Social da Previdência no que diz respeito aos debates sobre a deficiência, de forma que este se tornou aos poucos um grupo com reconhecida expertise neste campo. Após 2009, o Serviço Social do INSS promoveu ativamente discussões e capacitações, auxiliando, inclusive, juntamente com a equipe médica da instituição, na produção do próprio instrumento que avalia a deficiência para fins do BPC, em parceria com o Ministério do Desenvolvimento Social e Combate à Fome ${ }^{18}$.

A aproximação desses profissionais com a avaliação requerida pela LC 142/2013 acontece com protagonismo. Os desafios e as reflexões dos estudos sobre deficiência, ainda escassos no contexto nacional, são parte do cotidiano desses profissionais desde a implementação da avaliação social. Isso é notório, especialmente ao se considerar o fato de que o INSS é uma das primeiras instituições no Brasil a ser desafiada a implementar em escala nacional a Convenção.

Os resultados da pesquisa mostram que os profissionais que se dedicam a uma abordagem social da deficiência, como é o caso dos assis- tentes sociais, têm dificuldade para separar, na avaliação social, a restrição de participação devida à deficiência de restrições de outras ordens, como classe e gênero. Os profissionais entrevistados sentem-se compelidos pelo IFBrA a isolar a opressão pela deficiência de outras formas de opressão e sentem desconforto em realizar tal empreendimento. Segundo as instruções do IFBrA, o aplicador deve pontuar cada uma das 41 atividades com uma escala de valores a depender do desempenho do sujeito. Tal escala considera a dependência ou a independência para realizar a atividade. Para os assistentes sociais, no entanto, além dos impedimentos corporais e as barreiras direcionadas para eles, diferentes fatores influenciam a realização das atividades e a independência do segurado, conforme detalharemos a seguir.

Para os assistentes sociais, restrição de participação é um conceito multifacetado. As pessoas sofrem restrição de participação de várias ordens: econômica, racial, de gênero, etc. Tais formas de opressão, para eles, tanto agravam o desempenho das atividades no contexto da deficiência como podem compor a própria condição de pessoa com deficiência. Consideram, assim, desafiador determinar como cada forma específica de opressão contribuiu ao longo da vida, ou no presente, para a independência das pessoas na realização das atividades listadas pelo IFBrA.

As barreiras sociais colocadas para a deficiência, para os assistentes sociais entrevistados, são frequentemente agravadas ou reforçadas por outras condições de desigualdade. Um dos casos acompanhados, de uma mulher de 50 anos com visão monocular, é bastante paradigmático para compreender esse ponto. Há uma disputa no debate acadêmico e jurídico sobre se a visão monocular deveria ou não ser considerada deficiência ${ }^{19}$. A visão monocular ocorre quando a visão de um olho está preservada ${ }^{20}$. No caso acompanhado, Maria, que trabalhou a maior parte da vida como vendedora, considerava que as múltiplas barreiras que enfrentou eram resultado de sua deficiência. Maria não havia conseguido estudar pois a família a "achava burra, ainda mais com o olho com problema” (sic). Seu esposo e filha eram impacientes e insatisfeitos com sua performance nos serviços domésticos - ainda que nenhum dos dois participasse desses serviços. Desempregada, ela acreditava que não conseguia mais empregos em lojas porque era "feia e velha" (sic).

No atendimento observado, Maria acreditava que todas essas barreiras deviam-se a sua deficiência: não estudar por falta de apoio familiar, realizar serviços domésticos insatisfatórios (segun- 
do ela, porque não enxergava direito), e não conseguir emprego por sua idade e pela aparência física que acreditava ter. Era uma pessoa que, apesar de possuir uma deficiência considerada leve para muitos especialistas, sofria severa restrição de participação. Todos esses fatores, na verdade, possuíam forte componente da discriminação de gênero. Não ser inteligente para estudar, realizar solitariamente os serviços domésticos e estar insatisfeita com a própria imagem são características frequentemente atribuídas a mulheres, sendo elas pessoas com ou sem deficiência ${ }^{21}$.

Para efeitos da avaliação, o profissional analisou que tais formas de discriminação deveriam ser consideradas como barreiras para a participação igualitária de Maria e, portanto, agravantes para a deficiência. Ou ainda, a deficiência provocou uma autoimagem tão negativa que todas as críticas e barreiras sofridas eram aceitas sempre como justas. A formação da autorrepresentação depreciativa de Maria, provocada pela família, apareciam no seu discurso como o resultado natural de seu impedimento corporal. Sua visão monocular indesejada justificaria as opressões: as barreiras eram o resultado natural dos seus impedimentos. Não havia espaço para a crítica de gênero diante da desvantagem autoevidente da sua visão monocular e, portanto, havia ainda menor espaço para a construção de qualquer resistência a essas barreiras. Uma autoimagem positiva estava fora de seu alcance dada a desvantagem que sentia no ponto de partida.

Assim como nas questões de gênero, a baixa escolaridade, independente de ter sido ou não causada pela deficiência, foi considerada desafiadora pelos assistentes sociais. Pessoas com deficiência com baixa escolaridade tendem a enfrentar mais barreiras que pessoas sem deficiência com a mesma escolaridade ${ }^{22}$.

Como exemplo, os assistentes sociais entrevistados indicaram o item do IFBrA Comunicarse/Recepção de mensagens. Segundo o Manual de aplicação, o profissional deve considerar que tal atividade é responsável por "Compreender as mensagens (significados literais e implícitos) - Exemplos: compreender mensagens transmitidas por fala, escrita, gestos, sinais, símbolos, desenhos, fotografias, libras e comunicação tátil”" Uma interpretação literal do manual sugere que as dificuldades de comunicação a serem pontuadas se devem a algum impedimento sensorial (visão ou audição) no que diz respeito à acessibilidade, seja de adaptação de livros e imagens ou no domínio da sua forma prioritária de sua linguagem por seus pares. O Manual sugere que os limites de comunicação podem se dar por algum impedimento intelectual. Os assistentes sociais, no entanto, se esforçam por ampliar o conceito de deficiência e restrição de participação e tendem a considerar que os limites de compreensão gerados por baixa escolaridade podem fazer parte da avaliação.

Mesmo no que diz respeito às barreiras que se colocam diretamente ao corpo com impedimentos, os assistentes sociais buscam explorar ao máximo o contexto dessas barreiras. A aquisição de uma prótese ou outra forma de adaptação para realizar uma atividade determinada não é identificada como um correspondente imediato a pontuação indicada no Manual do IFBrA (75), cuja orientação diz "Realiza a atividade de forma adaptada, sendo necessário algum tipo de modificação ou realiza a atividade de forma diferente da habitual ou mais lentamente"23. Para os assistentes sociais, tanto a aquisição, a disponibilidade e a utilização dos recursos de acessibilidade devem ser contextualizados no momento da avaliação.

O conceito de deficiência dos assistentes sociais desafia as compreensões de restrição de participação que possam ser vistas como relacionadas exclusivamente ao corpo com impedimentos. Para eles, o esforço em isolar a deficiência de outras formas de opressão, muitas vezes, carece de sentido.

\section{Peritos médicos}

A avaliação da deficiência sob a égide da Convenção, conforme apresentado, não é uma novidade para a perícia médica da previdência social. A perícia médica do INSS avalia a deficiência para fins do BPC desde 1996 e acompanhou na prática suas mudanças conceituais no Brasil mais do que qualquer outra categoria profissional. Em 2009, já em trabalho conjunto com o Serviço Social, os médicos passaram a atuar desafiados pelo modelo social da deficiência assumindo o protagonismo das discussões de forma que, mesmo antes das mudanças normativas, estudos já mostravam os reflexos das discussões internacionais na sua prática profissional. Estudos recentes com os peritos médicos do INSS mostraram um vanguardismo no que diz respeito à avaliação da deficiência para o $\mathrm{BPC}^{23,24}$. Apesar da medicina ser uma área do conhecimento que historicamente tendeu a categorizar os $\operatorname{corpos}^{25}$ e a traduzir a deficiência como sinônimo dos impedimentos corporais, os médicos do INSS mostraram-se desafiados diante de situações em que o sujeito avaliado possuía um impedimento que, embora não 
fosse tradicionalmente identificado como correspondente a uma deficiência, era alvo de restrições de participação ${ }^{24}$.

Os dados desta pesquisa mostram que os desafios identificados nos estudos sobre a perícia médica para o BPC são similares no caso da aposentadoria das pessoas com deficiência. Os médicos se consideram desafiados na avaliação da deficiência, que tensiona com sua formação cujo enfoque reside nos impedimentos corporais. Nos novos modelos de avaliação, a deficiência é compreendida como restrição de participação em ambientes com barreiras. Assim, os impedimentos corporais, especialidade biomédica, não são compreendidos como determinantes da deficiência e não se confundem com ela ${ }^{25,26}$. Os peritos médicos do INSS entrevistados se esforçam para compreender a deficiência como restrição de participação, mas tensionam permanentemente com os determinantes dessa restrição.

Como o instrumento lista 41 atividades a serem preenchidas considerando-se a performance do sujeito em cada uma, analisar restrição de participação é considerado inevitável pelos médicos entrevistados. Nesse sentido, o IFBrA foi bem recebido pelos profissionais, uma vez que direciona o olhar dos avaliadores para as dimensões da vida que importam para considerar a restrição de participação correspondente à deficiência.

Há uma clareza para os peritos médicos entrevistados de que deficiência é um conceito multifacetado. A apropriação dos vários determinantes da deficiência, no entanto, acontece respeitando as tensões conceituais que se ancoram na formação biomédica dos profissionais. Para acomodar elementos do modelo social, os médicos descrevem os parâmetros da avaliação como subjetivos e objetivos. Quanto mais a avaliação se aproxima do conceito biomédico, como o uso dos laudos e pareceres para a determinação do início da deficiência, mais os médicos se declaram confortáveis com a atuação e confiantes na sua avaliação pericial. Por outro lado, nos casos em que o instrumento demanda uma leitura contextual das atividades do periciando, como atividades vinculadas a escolarização ou vida comunitária, os médicos acreditam estar avaliando uma dimensão subjetiva da deficiência e se dizem menos confortáveis e confiantes para a tarefa.

Mas, embora os peritos médicos relatem desconforto em avaliar a deficiência como restrição de participação, na prática atrelam invariavelmente seu julgamento a isso. Durante a avaliação, os médicos se sentem compelidos a considerar a restrição de participação como resultado do im- pedimento do sujeito. Estabelecer uma relação de causalidade entre o impedimento e a diversidade na realização das atividades listadas é um desafio constante para os profissionais. Os médicos relatam que muitas vezes as barreiras são evidentes, como no caso em que os sujeitos poderiam ter uma funcionalidade incrementada com o acesso a uma prótese ou a recursos de melhor qualidade. Mas, em geral, entendem que enxergar as barreiras nos casos apresentados são demandas colocadas pela política que ainda constituem entraves na avaliação.

Há um esforço dos peritos para adequar seu olhar para uma concepção de deficiência mais próxima do modelo social. Mas, para além da formação biomédica, há elementos institucionais que desafiam esses profissionais, como o tempo disponível para a avaliação e outras frentes de trabalho que não adotam a mesma concepção de deficiência. Como o INSS é a instituição responsável pelas perícias que conferem também as aposentadorias e os benefícios por incapacidade, os médicos alternam seus turnos entre a avaliação de sujeitos com deficiência que trabalham e sujeitos com e sem deficiência incapazes para o trabalho. Nesse sentido, a metáfora do interruptor é trazida por vários dos profissionais entrevistados: sentem que precisam ligar e desligar o conceito de deficiência a depender do objetivo da perícia a ser realizada.

Essa variedade de conceitos operacionalizados nos diferentes momentos da perícia médica pode gerar uma tensão nas cenas da avaliação executada na LC 142/2013. Para além da tendência vinda da formação médica de classificar os corpos, a tarefa dos médicos no INSS tem sido há vários anos aferir a capacidade/incapacidade para o trabalho dos candidatos a aposentadoria e outros benefícios.

\section{Pessoas com deficiência}

Apesar da existência de uma definição oficial de deficiência, o trabalho de campo procurou conhecer mais sobre como os segurados que foram buscar a LC 142/2013 entendem este conceito. Os dados mostram um conjunto complexo de elementos que apontam para diversas compreensões. O conceito de deficiência é instrumentalizado pelos segurados de acordo com suas histórias de vida e não seguem, necessariamente, a lógica definida pela Lei e pela Convenção. O uso do termo deficiência aparece como forma de justificar a busca pela aposentadoria, mas a forma como esse conceito é utilizado não corresponde ao seu significado normativo. 
Da mesma forma que o conceito de deficiência é utilizado de acordo com os pressupostos individuais dos participantes, ele é influenciado por, pelo menos, mais dois elementos fundamentais: a vivência da deficiência, vista aqui como elemento politizador da experiência; e a experiência do sofrimento, que aponta para elementos de outras ordens, para além da racionalização da deficiência como elemento diacrítico.

A deficiência, assim, pode ser apreendida pelos seguintes pontos de vista: um que leva em consideração as nomeações e as designações dadas por outrem com base em um conceito; outro que faz com que determinada experiência seja construída em torno de uma designação particular, que sugere identificação grupal. O primeiro seria dado pelos diferentes processos de nomeação e identificação criados pelo Estado ou por outras fontes de hegemonia discursiva. O IFBrA, nesse sentido, é um dos responsáveis por dizer quem é a pessoa com deficiência. O segundo, mais importante para a análise aqui realizada, aparece quando a pessoa racionaliza sua história e conta sua trajetória com base na ideia de deficiência. Ou seja, quando a categoria deficiência passa a fazer sentido na narração dos eventos que seguem - o que pode ser chamado de politização da deficiência.

Politização da deficiência é o fenômeno por meio do qual as pessoas se intitulam como "pessoas com deficiência”. Politiza no sentido de trazer leituras de realidade que levem em consideração as inúmeras dificuldades vivenciadas e, acima de tudo, pontua as dificuldades "na deficiência". Ou seja, para politizar o discurso sobre a deficiência, é necessário que o sujeito leia o mundo sob uma ótica específica, que demonstre que as restrições causadas pela deficiência tiveram impacto significativo em sua rotina de vida e em sua história.

Os segurados entrevistados expressam diferentes processos de politização da deficiência. $\mathrm{O}$ que é comum entre aqueles que se identificam como pessoas com deficiência é o reconhecimento histórico, social e político de que viveram histórias singulares em função da interação entre seus impedimentos corporais e as estruturas sociais pouco propícias para o pleno desenvolvimento. Este reconhecimento ou releitura de realidade de pessoa com deficiência traz consigo maior confiança na busca pelos direitos. Não apenas as pessoas buscam pela aposentadoria especial, mas também reforçam que este benefício é um direito adquirido por aquelas com deficiência.

Os segurados que fazem parte do grupo que vivencia ou vivenciou o processo de politização da deficiência apresentam um conhecimento mais específico da LC 142 e dos instrumentos correlatos. Nesse sentido, grande parte deles já conhecia o IFBrA. Esse conhecimento prévio faz com que os mesmos tragam reflexões elaboradas sobre o conteúdo e a aplicação do instrumento pelos técnicos do INSS.

No que se refere ao conteúdo, os segurados questionam os objetivos das perguntas realizadas pelos profissionais. Não há indícios de oposição às perguntas, entretanto, tecem alguns questionamentos sobre as necessidades do conjunto de questões. Uma das possíveis interpretações desses questionamentos vem com a reflexão da interação tensa entre os diferentes modelos de deficiência em disputa na contemporaneidade. Por um lado, o conceito biomédico de deficiência pontua no corpo as definições, por outro, o IFBrA traz questões sobre a vida em sociedade de uma forma ampla, e não apenas baseado nos impedimentos corporais de um sujeito específico.

Porém, alguns segurados entrevistados questionam elementos que não estão expressos no IFBrA. Esse questionamento vem ao encontro da definição da Convenção e faz sentido quando analisado à luz do modelo social da deficiência. Mesmo com a visão ampla proposta pelo IFBrA, elementos da ordem das restrições possíveis, que englobam atividades não realizadas em função da deficiência, não são levados em consideração. Os segurados não trazem críticas ao instrumento, apenas apontam questões que poderiam ser melhor trabalhadas para contemplar as restrições de participação trazidas pela deficiência. É importante ressaltar que esse tipo de discurso faz parte do grupo de pessoas que estão engajadas na vivência da deficiência e estabelecem relações diversas entre aspectos de ordem corporal e socioestrutural. Alguns segurados ressaltam, ainda, a necessidade da escuta das pessoas com deficiência por parte dos gestores e dos elaboradores dos instrumentos de avaliação do INSS. Um dos argumentos é de que o instrumento também precisa levar em consideração a expectativa das pessoas com deficiência.

O segundo grupo de segurados busca a aposentadoria por diferentes razões. O que eles têm em comum é o fato de não construírem um discurso específico sobre a deficiência, inserindo-a em um conjunto de sofrimentos que os levaram à busca pela LC 142/2013. Os segurados não se definem, necessariamente, como pessoas com deficiência e, assim, apresentam relações com a Lei e com o IFBrA distintas daquela dos sujeitos que vivenciaram a politização da deficiência. 
As narrativas usadas pelos segurados deste grupo são compostas por sofrimentos que fazem com que a busca pela aposentadoria seja necessária. A necessidade se dá pela impossibilidade de continuar a exercer as tarefas pelas quais eram responsáveis no dia a dia. A busca pela aposentadoria é posta como um caminho inevitável em função das condições de saúde, que, na sua grande maioria, são relatadas como tendo pioras sucessivas ao longo do tempo, chegando a estados incontroláveis.

Esse é outro ponto comum dos segurados que fazem parte desse grupo: eles não elaboram uma distinção evidente entre deficiência e doença. Em diferentes narrativas podemos perceber um vínculo estabelecido pelos segurados entre as dificuldades vividas em função de determinada patologia e as limitações em seu corpo e no desempenho de suas atividades. Da mesma forma, esses são os casos que desafiam as avaliações clássicas sobre deficiência. Eles não acionam para a reflexão apenas os tipos mais comuns de deficiência (física, auditiva, sensorial, visual, etc.), mas trabalham com outros impedimentos corporais que também podem causar restrição de participação, como as doenças crônicas ${ }^{27}$. Falamos aqui, por exemplo, dos segurados que buscavam a aposentadoria da LC 142 em função de hérnia de disco, mal de Parkinson, HIV ou diferentes tipos de cânceres.

Entretanto, mesmo buscando a Lei Complementar, esses segurados não se nomeiam ou não referem a si mesmos como pessoas com deficiência. A deficiência aparece como um fenômeno corporal que prejudica o desempenho de suas atividades e não como um conceito chave para a compreensão de suas experiências vividas e/ou de suas mudanças de rotina. E mais, os segurados fazem uso de narrativas que apontam para os problemas ocasionados por esta questões especialmente na esfera do trabalho. Geralmente, as histórias contadas neste sentido são pontuadas no tempo: a partir de um evento específico, o sofrimento começou a imperar e exigiu que alternativas financeiras ao trabalho que estava sendo realizado fossem procuradas. Por esse motivo, nem sempre fenômenos de tempos passados e distantes temporalmente são levados em consideração pelos segurados. O que está em jogo, segundo esse conjunto de segurados, são os fenômenos que aconteceram que dificultam o exercício o trabalho.

\section{Conclusão}

As reflexões aqui apresentadas trazem questões sobre as formas como peritos médicos, assistentes sociais e segurados do INSS que se candidataram a aposentadoria e foram avaliados segundo o IFBrA utilizam o instrumento e/ou o percebem na interação. Tais reflexões fazem parte de um movimento maior de validação e pretendem contribuir para reflexões globais sobre a LC 142/2013 e seus impactos na sociedade brasileira.

Os resultados da pesquisa mostram uma tensão constante entre o conceito de deficiência dos profissionais e das pessoas com deficiência e o conceito que compreendem ser operacionalizado pela Lei. De um lado, temos um conjunto de elementos que estão dispostos nas normativas oficiais. Por outro, temos profissionais instrumentalizando esses conceitos e temos pessoas se apropriando de diferentes concepções e fazendo uso em contextos particulares e diversos.

Foram identificadas dificuldades e desafios na instrumentalização dos conceitos trazidos pela Convenção por meio do IFBrA. Os assistentes sociais e os peritos médicos relataram dificuldades variadas na utilização do instrumento e os segurados que foram em busca dos seus direitos fazem uso de uma complexidade de formas de expressão da deficiência que, muitas vezes, não é captada na avaliação social ou na perícia médica.

O contexto da aplicação do IFBrA apareceu como um elemento importante e que poderá ser melhor explorado futuramente. Os tempos e as rotinas do INSS, bem como as diversas demandas a que os profissionais são submetidos, produzem impacto na aplicação do instrumento e na consequente assimilação de alguns de seus objetivos. Os segurados, por sua vez, vivenciam situações diversas que também são consequências do contexto no qual o IFBrA é aplicado.

Outra questão particularmente relevante que emergiu com os dados da pesquisa foi a importância das experiências pessoais das pessoas com deficiência e da formação dos profissionais para as definições de deficiência. As formas como os diferentes sujeitos se posicionam sobre o IFBrA e sobre a LC 142/2013 são influenciadas pelo conjunto de informações ou vivências trazidas em histórias particulares. Esse é outro ponto que pode ter impacto na aplicação e aceitabilidade do instrumento. 
O terceiro ponto, que parece ser um dos centrais para o presente artigo, diz respeito à dificuldade na instrumentalização do conceito de deficiência. Em grande medida, essa dificuldade se dá em função das experiências e expectativas diferenciadas que cada sujeito carrega quando da reflexão sobre deficiência. Em outro sentido, pode ser pensada também como consequência da disputa conceitual em voga, que pondera entre pelo menos dois modelos concorrentes e, muitas vezes, antagônicos.

\section{Colaboradores}

EL Pereira e L Barbosa participaram igualmente da coleta e sistematização dos dados e da redação do artigo.

\section{Agradecimentos}

Os autores agradecem aos professores Daniela da Silva Rodrigues, Heleno Rodrigues Corrêa Filho, Edgar Merchan-Hamman, Maria da Graça Höefel e William Rosa Souza e aos estudantes que auxiliaram na pesquisa de campo: Ana Paula do Nascimento Barros, Gisele Boaventura, Felipe Xavier, Ana Carolina Castro da Cunha, Camila Nogueira, Ellen Furtado e João Armando Alves. Por fim, agradecem o financiamento da pesquisa pelo Ministério da Previdência Social e a Fundação de Amparo à Pesquisa do Distrito Federal. 


\section{Referências}

1. Brasil. Lei Complementar no 142, de 8 de maio de 2013. Regulamenta o $\$ 1^{\circ}$ do art. 201 da Constituição Federal, no tocante à aposentadoria da pessoa com deficiência segurada do Regime Geral de Previdência Social - RGPS. Diário Oficial da União 2013; 9 maio.

2. Brasil. Decreto no 6949, de 25 de agosto de 2009. Promulga a Convenção Internacional sobre os Direitos das Pessoas com Deficiência e seu Protocolo Facultativo, assinados em Nova York, em 30 de março de 2007. Diário Oficial da União 2009; 26 ago.

3. Davis L. Enforcing normalcy: disability, deafness and the body. New York: Verso; 1995.

4. Diniz D. O que é deficiência. São Paulo: Editora Brasiliense; 2007.

5. Barnes C, Barton L, Oliver M. Disability Studies Today. Cambridge: Polity Press; 2002.

6. Shakespeare T. Disability Rights and Wrongs. New York: Routledge; 2006.

7. Corker M, Shakespeare T. Maping the Terrain. In: Corker M, Shakespeare T, editors. Embodying disability theory. London: Continium; 2004. p. 1-17.

8. Hugues B. Disability and the Body. In: Barnes C, Barton L, Oliver M, editors. Disability Studies Today. Cambridge: Polity Press; 2002. p. 58-76.

9. Franzoi AC, Xerez DR, Blanco M, Amaral T, Costa AJ Khan P, Maia SR, Magalhães C, Maior IL, Pelosi MB, Santos NQ, Thedim M, Vilela LVO, Riberto M. Instrumento de Classificação do Grau de Funcionalidade de Pessoas com Deficiência para Cidadãos Brasileiros: Índice de Funcionalidade Brasileiro - IF-Br. Acta Fisiatrica 2013; 20(3):164-170.

10. Brasil. Lei 13.146, de 6 de julho de 2015. Lei Brasileira de Inclusão. Diário Oficial da União 2015; 7 jul.

11. Brasil. A Portaria Interministerial AGU/MPS/MF/ SEDH/MP no 1, de 27/01/2014. Aprova o instrumento destinado à avaliação do segurado da Previdência Social e à identificação dos graus de deficiência, bem como define impedimento de longo prazo, para os efeitos do Decreto ${ }^{\circ} 3.048$, de 6 de maio de 1999. Diário Oficial da União 2014; 28 jan.

12. Minayo MCS. Pesquisa Social: Teoria, método e criatividade. 22a ed. Petrópolis: Editora Vozes; 1994.

13. Creswell J, Clark VLP. Designing and conducting mixed methods research. London: Sage Publications; 2007.

14. Creswell JW. Research Design Qualitative, Quantitative and Mixed Methods Approaches. $2^{\text {nd }}$ ed. California: Sage Publication, Inc.; 2003.

15. Cassiani SHDB, Caliri MHL, Pelá NTR. A teoria fundamentada nos dados como abordagem da pesquisa interpretativa. Rev Latino-americana de Enfermagem 1996; 4(3):75-88.

16. Braga L, Cabra MSR. Serviço social na previdência: trajetória, projetos profissionais e saberes. São Paulo: Cortez Editora; 2007.
17. Brasil. Decreto no 6.214, de 26 de setembro de 2007 Regulamenta o benefício de prestação continuada da assistência social devido à pessoa com deficiência e ao idoso de que trata a Lei no 8.742, de 7 de dezembro de 1993, e a Lei no 10.741, de 1o de outubro de 2003, acresce parágrafo ao art. 162 do Decreto no 3.048, de 6 de maio de 1999, e dá outras providências. Diário Oficial da União 2007; 27 set.

18. Brasil. Ministerio do Desenvolvimento Social e Combate a Fome (MDS). Avaliação da nova modalidade de concessão do Benefício de Prestação Continuada (BPC) à pessoa com deficiência com base na Classificação Internacional de Funcionalidade, Incapacidade e Saúde (CIF). Brasília: MDS; 2011.

19. Queiroz AV. Deficiência e Justiça: um estudo de caso sobre a visão monocular. Brasília: Universidade de Brasília; 2011.

20. Fernandes MCR, Marin GP, Nepomucen ABV, Nascimento FMd, Rocha EM. O impacto da visão monocular congênita versus adquirida na qualidade de visão autorrelatada. Arquivos Brasileiros de Oftalmologia 2010; 73(6):521-525.

21. Morris J, editor. Encuentros con desconocidas: Feminismo y discapacidad. Madrid: Narcea; 1996.

22. Oliveira LMB, Secretaria de Direitos Humanos da Presidência da República (SDH/PR). Cartilha do Censo 2010 - Pessoas com Deficiência. Brasília: Secretaria Nacional de Promoção dos Direitos da Pessoa com Deficiencia; 2012.

23. Barbosa L, Diniz D, Santos W. Diversidade corporal e perícia médica: novos contornos da deficiência para o Benefício de Prestação Continuada. Rev Textos \& Contextos 2009; 8(2):377-390.

24. Santos W, Diniz D, Pereira N. Deficiência e perícia médica: os contornos do corpo. Reciis 2009; 3(2):16-23.

25. Canguilhem G. O normal e o patológico. São Paulo: Editora Forense Universitária; 1995.

26. Thomas C. Disability and Impairment. In: Swain J, French S, Barnes C, editors. Disabling Barriers - Enabling Environments. London: SAGE Publications; 2004. p. 21-27.

27. Wendell S. Unhealthy disabled: Treating Chronic Illnesses as Disabilities. Hypathia 2001; 16(4):17-33.

Artigo apresentado em 10/03/2016

Aprovado em 04/07/2016

Versão final apresentada em 06/07/2016 